\title{
Psicologia e publicidade: velhos e novos encontros
}

\section{RESUMO}

A escassez de discussão e de proposição de novas perspectivas para a interface psicologia/publicidade foi o mote para o trabalho teórico, prático e ético junto ao que chamamos de operadores do consumo, sistematizado em um projeto acadêmico. Neste escrito, buscamos discutir, com base na psicologia social contemporânea, questões pertinentes a essa interface levantadas ao longo do projeto. Questionamos o estatuto da comunicação na publicidade e a sua possibilidade de comunicar algo outro, de forma diversa e com outros efeitos. As análises apontaram para um distanciamento da publicidade das concepções recentes de comunicação e a necessidade do campo contemplar os sujeitos sociais tendo em vista a crescente criação de outros modos de vida.

\section{PALAVRAS-CHAVE \\ psicologia \\ publicidade \\ modos de subjetivação}

\section{ABSTRACT}

The lack of discussion and proposals of new perspectives for the interfaces psychology/advetising leads to a theoretical, practical and ethical work merged in an academic project with what we are calling consumption operators. The purpose of this writing is to discuss, based on contemporary social psychology, relevant questions concerning this interface that rose during the project. We discussed the status of communication regarding advertising and the possibility to communicate something else, differently and with other effects. The analysis pointed to a distance between advertising and recent concepts of communication and also the need to take into account social subjects having in mind the increased creation of other ways of life.

\section{KEY WORDS}

psychology

advertising

subjectivation ways

\section{Inês Hennigen}

Professora do Programa de Pós-graduação em Psicologia Social e Institucional da UFRGS/RS/BR

ineshennigen@gmail.com

\section{Ângelo Brandelli Costa Graduando em Psicologia na UFRGS/RS/BR angelobrcosta@uol.com.br}

A psicologia, tanto na clínica individual quanto no trabalho com coletivos sociais, cada vez mais se defronta com o consumo como algo fundamental nas vivências subjetivas de crianças, jovens e adultos. A resposta dos psicólogos, muitas vezes, é fazer coro com pensadores de diferentes disciplinas que temem ou já apontam a existência de uma espécie de "precarização subjetiva" na contemporaneidade. Essa seria efeito da profusão de imagens, veiculadas pela mídia, que venderiam o estatuto de ser a partir do ter, da transformação de tudo - inclusive pessoas e suas relações - em mercadoria (Bauman, 2008; Bucci \& Kehl, 2004; Severiano, 2006).

A questão que nos colocamos é como, não desconhecendo nossa condição de sociedade de consumo, podemos superar certa perplexidade e paralisia que a essa condição parece estar gerando. Não que a análise crítica que muitos têm empreendido seja por nós descartada por ser equivocada ou inócua. Ao contrário, concordamos com aqueles que apontam o consumo como atravessando os modos de subjetivação contemporâneos e acreditamos que sua problematização é fundamental. A sensação de paralisia decorre mais do fato de que, fora uma crítica que, com maior ou menor ênfase, tende a "demonizar" o consumo, a impressão é a de que nada "politicamente correto" e/ou novo pode ser dito ou proposto nesse âmbito.

Pensamos que um ponto importante é o foco da dita crítica. Parece-nos que, muitas vezes, a crítica realizada acaba sendo tão ampla (uma crítica à sociedade capitalista como um todo) que, apesar de pertinente em muitos aspectos, esvazia-se e perde potência no que tange à ação. E, quando o capitalismo não é o alvo, a crítica recai sobre a mídia e sua influência sobre os sujeitos. Essa é identificada como o dispositivomor no fomento ao consumo, no culto à imagem, na mercantilização e banalização da vida. Mais uma vez as reflexões parecem não apontar alternativas, a não ser maior regulação dos meios de comunicação, o que sempre gera muitas resistências e controvérsias pela valoração da liberdade em nossa sociedade.

Por isso, buscando uma aproximação entre psicologia social e a temática do consumo ${ }^{1}$, optamos por trabalhar com o que estamos chamando de operadores do consumo, instâncias nas quais as questões do consumo se operacionalizam na sociedade contemporânea: agências de publicidade, consultorias de pesquisa de mercado, órgãos de defesa do consumidor, etc. Nosso objetivo é buscar, a partir da interlocução com esses operadores, traçar novos horizontes, outras compreensões e práticas relativas ao consumo, quem sabe com outros efeitos nos modos de subjetivação. 
No presente artigo, propomos uma discussão relativa ao campo da publicidade, certamente o mais identificado como o fomento do consumo. A expressão publicidade, no Brasil, refere-se a uma área de atuação e de estudos ${ }^{2}$ das Ciências da Comunicação que tem como finalidade principal a divulgação de produtos e serviços com fins comerciais. Em função disso, mesmo parecendo um tanto óbvio, consideramos pertinente perguntar: o que a publicidade comunica; a quem comunica; como sabe que está comunicando o que almeja; poderia comunicar algo outro, de forma diversa, com outros efeitos?

Pensamos que, problematizando essas questões, será possível deslocar o eixo que tem marcado as relações entre psicologia e publicidade, para que possam advir novas compreensões e práticas àqueles que trabalham nessa interface. Iniciamos falando sobre o lugar que tem sido tradicionalmente demandado à psicologia no campo da publicidade e o que ela tem lhe oferecido, para então trazer algumas concepções e questionamentos que têm sido produzidos pela psicologia social nas últimas décadas e que podem contribuir para a discussão das questões acima lançadas, visando o desenho de um outro horizonte.

\section{Apontamentos históricos}

Para contextualizar o início da interface psicologia/ publicidade, é importante apresentar alguns aspectos pontuais da história do marketing no século $X X$, pois foram os seus desdobramentos que produziram a necessidade da incorporação de saberes outros, como os psicológicos, a esse campo.

Na década de 1930, a partir de um produto já fabricado, a estratégia principal era apresentá-lo para a venda utilizando sua própria imagem. O produto era a fonte mesma da imagem, vinculada sobretudo em cartazes e outros impressos (Fontanelle, 2004). Nessa época, pós-Depressão, iniciou-se um deslocamento onde a ótica produtivista deu lugar à ótica do consumidor, sendo necessário, portanto, compreender porque as pessoas compravam. Disso decorreu uma cientifização das práticas do marketing e o surgimento da pesquisa de mercado, ancorada no uso de técnicas de diferentes disciplinas como estatística, psicologia, sociologia e afins (Fontanelle, 2008).

A partir da década de 1950, começou um processo de associação/substituição da imagem do produto a/por imagens outras na sua comunicação: inicialmente essas eram veiculadas junto ao produto e, gradativamente, a imagem do produto deu lugar a uma imagem-conceito. Isso aconteceu tanto em função da necessidade das empresas se diferenciarem (a produção em massa tornava os produtos homogêneos), como devido ao surgimento da televisão e outros meios que permitiram a produção e uso de imagens comerciais de uma maneira muito mais veloz, abrangente e espetacularizada. Nesse período surgem as chamadas pesquisas de motivação para subsidiar uma estratégia destinada a vender "não o bife, mas o chiado; não o sabonete, mas o sonho de beleza; não as latas de sopa, mas a felicidade familiar" (Hobsbawm, 1995, p. 496).

Duas escolas de pensamento da psicologia responderam de forma mais consistente e contínua às necessidades que vinham se produzindo: a comportamental e a psicanalítica. A primeira se fez presente no campo das vendas e do advertising e seu foco recaiu sobre o anúncio do produto; a segunda contribuiu para a formatação da pesquisa motivacional, que buscava acessar as necessidades e desejos (inconscientes) dos consumidores.

A abordagem comportamental inicial propunha que o comportamento resultava dos estímulos e reforços do ambiente; sua contribuição aconteceu a partir da crença de que a manipulação cuidadosamente planejada de estímulos poderia induzir às ações desejadas. Essa concepção foi amplamente aplicada à aprendizagem humana e balizou os estudos de Watson sobre o comportamento do consumidor no início do século XX.

Já a abordagem psicanalítica se preocupou em conhecer as vontades e desejos dos consumidores, suas necessidades inconscientes, explorando "a profundidade do estímulo do marketing na mente dos consumidores" (Fontanelle, 2008, p. 147). Ligada às pesquisas motivacionais, através dessa abordagem buscavam-se os valores e as crenças que os sujeitos projetavam nos objetos e, a partir disso, passou-se a representá-los através das imagens publicitárias. Conforme Calligaris (2008), a idéia, desenvolvida pelo psicanalista Ernst Dichter, de que os consumidores tinham duas motivações básicas (busca de poder social e sucesso sexual) foi inovadora no marketing dos anos 50. Assim, uma peça publicitária que almejasse ser eficiente precisaria vincular o produto a alguma dessas motivações, ou às duas.

Mesmo remontando à primeira metade do século passado, as idéias e estratégias da matriz psicanalítica e da comportamental ainda se fazem presentes no discurso publicitário atual. Importante ressaltar que a segunda recebeu novo vigor a partir da ascensão dos estudos cognitivos e das neurociências. No Brasil, o grupo de pesquisa Consuma da UnB trabalha com essa perspectiva, desenvolvendo estudos do comportamento do consumidor a partir de variadas abordagens, dentre as quais se destaca a cognitivosocial.

Já no âmbito da psicologia social, Wachelke e Segala (2005) apresentam duas outras perspectivas que julgam serem de grande valia para o campo: os estudos das atitudes, mais próximo à cognitivo-social, e a teoria das representações sociais.

Segundo os autores, os estudos sobre atitudes buscam a explicitação das condições em que as pessoas mudam de atitudes em relação aos objetos sociais, das 
influências das variáveis que as tornam mais ou menos favoráveis aos objetos. A contribuição desse referencial teórico reside no estudo da extensão da influência de determinadas peças de comunicação no público e suas atitudes. Já o estudo das representações sociais leva em conta as chamadas teorias do senso comum, mantidas por determinados grupos sociais, e as formas como elas influenciam na tomada de decisão e nas práticas desses coletivos. Essa teoria ganhou importância "devido à forte influência dos meios de comunicação de massa, fazendo do senso comum uma forma de conhecimento passível de mudança relativamente veloz e especifica a grupos" (Wachelke; Segala, 2005, p. 11).

Analisando as perspectivas teóricas apresentados até aqui, é curioso constatar que, por mais que atualmente várias vozes (Morin, 2008; Wolton, 2006) contestem a idéia de um sujeito frágil a mercê dos meios de comunicação, parece que na interface psicologia/publicidade continua-se buscando uma espécie de chave para o conhecimento "profundo" do consumidor a fim de potencializar a mensagem publicitária - a chamada emissão - acreditando que tal saber poderia torná-la certeira.

A crença no poder manipulatório da mídia e, especialmente, da publicidade alicerça-se em uma conjetura: seria possível dispor de estratégias persuasivas, inclusive subliminares, que levassem as pessoas a agir até, eventualmente, contrariando seus verdadeiros interesses (Rocha, 2007). Estratégias essas que seriam possíveis a partir dos conhecimentos produzidos pela psicologia. Lendas urbanas como as da propaganda subliminar (Bighetti, 2003) circulam inclusive no meio acadêmico: em contato com estudantes de psicologia e comunicação, e mesmo com profissionais já em atuação na publicidade, os pedidos para saber "como entrar na mente dos consumidores" ou "como funciona a propaganda subliminar" não são, de forma alguma, raros.

Sousa (2006) afirma que vários autores, a partir dos estudos sobre propaganda de Estado desenvolvidos durante a I Guerra e influenciados pelo positivismo e psicologia behaviorista, passaram a defender a tese de uma influência direta dos meios de comunicação sobre as pessoas, o que poderia provocar, por si só, mudanças de comportamento. Essas idéias passaram a ser conhecidas como teoria hipodérmica ou teoria da bala mágica. Ambas as denominações pretendiam traduzir, metaforicamente, que a comunicação se daria como balas mágicas, que sempre atingiam seus alvos, ou como agulhas hipodérmicas, "pois os efeitos dos medicamentos injetados tendem a ser os mesmos nas diferentes pessoas" (Sousa, 2006, p. 493).

Segundo Bighetti (2003), somou-se a isso a crença, propagada na década de 1950, de que as empresas de comunicação visariam manipular as mentes para o consumo. Isso seria feito por mensagens abaixo do nível da consciência, denominada propaganda subliminar.
Essa "técnica" nunca recebeu um status científico. O próprio autor do célebre "experimento" que emitia a mensagem "coma pipoca" entre uma cena e outra de um filme admitiu à revista Advertising Age, em 1963, que seus experimentos nunca tiveram sucesso. Mas a idéia já estava difundida, criando uma representação social persistente. Bighetti (2003, p. 48) afirma que hoje "este tipo de 'criação' é comprovadamente ineficiente e deve ser deixado de lado, descansando na categoria das curiosidades".

Para nós, recuperar a discussão sobre propaganda subliminar tem uma utilidade outra: servir de metáfora para expressar os pressupostos e as práticas de uma determinada interface entre psicologia e publicidade ainda muito em voga e que buscamos transcender.

Nela almeja-se o "desvelamento" do sujeito, supondo, implícita ou explicitamente, que o mesmo é dotado de uma interioridade psicológica - natural, estável e generalizável - passível de apreensão. Essa concepção pode ser considerada produto e herança de uma psicologia que preconiza, entre outras coisas, uma oposição entre o individuo e o social, sendo esse tomado como uma fonte de influência sobre aquele. Assim, articulam-se duas concepções aparentemente paradoxais: a existência de uma unidade psicológica interior ao sujeito e a possibilidade do mesmo vir a ter seu comportamento alterado a partir da influência do "meio".

A idéia de manipulação, de uma influência direta dos meios de comunicação, se constrói, portanto, quando se concebe um sujeito que tem uma "verdade" ou essência interior, mas que pode se vergar conforme a força do que lhe é apresentada por aqueles que, conhecendo o que ele porta de mais íntimo ou os processos que lhe determinam, utilizam isso para conseguir que ele adote certas atitudes ou comportamentos (seja comprar um produto, assumir uma forma de ser ou adotar uma posição política).

No entanto, a tese do sujeito passivo, marionete da mídia e da publicidade, está sendo cada vez mais contestada. Como afirma Wolton (2006, p. 32), “a comunicação é menos manipuladora do que se diz. Seria antes uma espécie de jogo de tolos em que ninguém é tolo". Contudo, isso não quer dizer, de modo algum, que a mídia em geral e a publicidade em particular não produzam efeitos importantes - e por vezes preocupantes - nos modos de subjetivação na contemporaneidade.

Conhecer os processos pelos quais isso se produz afigura-se fundamental para buscar alternativas que possibilitem à publicidade superar a busca incessante pela mensagem certeira e cumprir a sua função de comunicar.

\section{Modos de subjetivação e publicidade no contemporâneo}

A partir do questionamento que a psicologia realizou nas últimas décadas sobre seus discursos e práticas ${ }^{3}$, 
desenvolveu-se uma nova compreensão acerca do processo de subjetivação (Hennigen, 2006). Esse aconteceria como efeito das configurações sociais, das práticas discursivas tomadas como regimes de verdade em certo tempo e espaço social. Nessa perspectiva, o sujeito, à medida que se constitui, também constrói o mundo social. Quebra-se a idéia de um sujeito prévio, apreensível em sua essência, constituído independente dos discursos que circulam socialmente. Por isso, falase em posições de sujeito ou modos de subjetivação, que são plurais e dinâmicos.

Nesse sentido, não há, por exemplo, um conceito atemporal que circunscreva o que é ser adolescente, uma posição de sujeito que podemos ocupar. Começou-se a construir a adolescência a partir do que se dizia sobre ela nos discursos da medicina, educação, direito, psicologia e também da mídia (Fischer, 1996). De uma época em que a transição da infância para a adultez acontecia quase automaticamente, passouse para outra em que adolescência era sinônimo de "rebeldia", até chegar-se hoje ao universo dos tweens, das irmães e dos kidults ${ }^{4}$. Assim, a adolescência não é um momento cronológico natural do desenvolvimento humano: sua existência e valor são produzidos. Logo, enquanto se está buscando compreendê-la, na verdade o que se está fazendo é engendrando-a.

Por um lado, o sujeito é processual e não uma essência ou uma natureza: não há sujeito, mas processo de subjetivação. Por outro lado, subjetivação é o processo por meio do qual os indivíduos e coletividades se constituem como sujeitos, ou seja, só valem na medida em que resistem e escapam aos poderes e saberes constituídos. Os poderes e saberes suscitam resistências (Parente, 2004, p. 56).

Agora, após apresentarmos uma concepção mais contemporânea acerca do processo de subjetivação, chega o momento de começar a retomar as perguntas que foram lançadas no início do texto: o que tem constituído a comunicação publicitária; a quem ela tem se dirigido; como sabe que tem comunicado o que se propõe a comunicar?

Fazer esses questionamentos implica trazer a tona uma concepção de comunicação, mas, para tanto, não cremos ser necessário lançar mão das teorias da comunicação, suas premissas, oposições ou convergências. Temos ciência de que nossas discussões acabam tangenciando essa temática, mas somente à medida que abrem caminho para pensar a interface psicologia/publicidade. Por isso, vamos ser econômicos e nos atermos a um aspecto da comunicação que vem sendo ressaltado por diferentes pensadores e que é considerado por Maffesoli (2008, p. 25) como "o cerne da questão: o que comunicar quer dizer? Estar junto, estar em relação, estar em vibração comum".
Segundo esse autor, não há uma diferença substancial entre informação e comunicação, pois ambas remetem à partilha, ao laço social, à criação de um destino comum. E ele assinala que, apesar de a comunicação estar cada vez mais segmentada, ser dirigida a variados públicosalvos, esses só são esboçados para o oferecimento de produtos, sendo que o aspecto tribal, a dimensão pósmoderna do fenômeno, acaba não sendo considerada. Por isso, a palavra comunicação, para Maffesoli (2008, p. 21), "serve também para encarnar o retorno dessa velha idéia que é o imaginário, ou seja, o fato de que se vibra com os outros, em torno de alguma coisa, seja qual for essa coisa".

Wolton (2006) ressalta a busca da relação e do compartilhar como imanente ao processo comunicacional e afirma que a expressão é só o primeiro tempo da comunicação. O segundo tempo, relativo à recepção, à construção da relação, é o mais complicado e o que precisa ser melhor contemplado. "Quanto mais as técnicas permitem a expressão, mais a questão do feedback, do retorno, torna-se mais importante" (Wolton, 2006, p. 14). A centralidade do receptor, de acordo com ele, é efeito de dois fenômenos concomitantes: o compartilhamento de muito mais informações entre indivíduos, que também são consumidores confrontados com uma gama crescente de escolhas, ou seja, o cidadão-consumidor encontrase numa situação de exposição e de interação.

Nesse cenário, aparecem duas figuras contraditórias: o cidadão-consumidor hiperativo, que organiza sua vida a partir de terminais e sistemas de informação interativos e o cidadão-consumidor passivo perante a publicidade e a mídia. Então, Wolton (2008, p. 35) pergunta: "por que o mesmo indivíduo seria passivo e manipulado quando recebe uma mensagem e inteligente quando the vendem um serviço em que solicitam que seja ativo?".

Em função da inteligência do receptor, Morin (2008, p. 12) afirma que a comunicação não se esgota na presunção da eficácia do emissor e que "a compreensão não está ligada à materialidade da comunicação, mas ao social, ao político, ao existencial, a outras coisas".

Com base nessas considerações, acreditamos que o questionamento acerca do caráter da comunicação publicitária se mostra pertinente. Hoje, em qualquer circuito de marketing/publicidade, se fala de segmentos de mercado, de perfis diferenciados de consumidores. Contudo, o "encontro" com os sujeitos acontece somente a partir das pesquisas de mercado, que são feitas com o objetivo de oferecer subsídios para a produção das estratégias e campanhas. Soma-se a isso o fato de que, no campo acadêmico da Comunicação Social, a publicidade praticamente não realiza estudos de recepção de suas produções. Jacks e Piedras (2006) mostraram que, na década de 90, somente três pesquisas acadêmicas foram desenvolvidas tendo como objetivo investigar a recepção da publicidade. 
Ao mesmo tempo, segundo profissionais da área, proporcionalmente ao volume de produções, são escassos os estudos de impacto das campanhas, tanto do ponto de vista da opinião do público quanto do retorno do investimento do anunciante. Em suma, a publicidade só tem se (pre)ocupado em qualificar uma das dimensões da comunicação, o pólo da emissão ou a expressão. Mas comunicação não implica em relação?

Portanto, não é a toa que, a respeito da publicidade, Toscani (1996, p. 27) disse que "a publicidade não vende nem produtos nem idéias, mas um modelo falsificado e hipnótico de felicidade que ninguém mais acredita". Daí decorre a principal idéia do autor que considera a publicidade e suas técnicas defasadas: "os publicitários não cumprem a sua função: comunicar. Carecem de ousadia e de senso moral. Não refletem sobre o papel social, público e educativo da empresa que lhe confia o orçamento" (Toscani, 1996, p. 25).

Para nós, a questão principal não reside em acreditar ou não nas mensagens publicitárias, pois aderir a um discurso não depende da crença no mesmo. Diante de um filme dramático, por exemplo, nos envolvemos com a história e eventualmente choramos, nos afetamos mesmo sabendo que se trata de uma ficção (não entra em questão a sua veracidade, não questionamos o fato de estarmos ou não sendo iludidos ou manipulados); a partir de um processo semelhante, o consumidor participa do jogo publicitário (Rocha, 2007). Por isso, pensamos que o fundamental é atentar para os efeitos das narrativas publicitárias no processo de subjetivação. Acompanhamos Morin (2008, p. 18), quando ele diz que "mais do que a manipulação, precisamos estudar e compreender a relação da mídia com nossos imaginários".

A princípio pode parecer exagerado tomar a cultura das imagens e especificamente a publicidade como central nos modos de subjetivação contemporâneos. Contudo, se considerarmos a posição de alguns psicanalistas acerca da constituição do sujeito psíquico, fica mais claro como o imaginário tem um papel legítimo nesse processo.

Um sujeito, em princípio, se constitui por dois caminhos. De um lado, se identifica aos valores, obrigações, tradições que cada um recebe de sua cultura étnica, nacional, familiar etc, (estas são as identificações simbólicas). Do outro, se esforça para coincidir com a imagem que poderia satisfazer aos outros [...] (Calligaris, 1994, p. 50).

No transcorrer da modernidade, o peso relativo desses dois caminhos altera-se. A nação da qual fazemos parte deixa de ser a nossa derradeira morada, pois podemos facilmente emigrar, viajar. A família, o grupo a que originalmente pertencemos, tornase o grupo em relação ao qual reivindicamos nossa independência; a família que porventura constituímos é fruto das intempéries dos afetos e humores e não de tradições ou contratos sociais. A posição social depende muito mais do êxito pessoal e profissional do que de algum determinismo do lugar social de nascimento. Então, pode-se dizer que, na falta de identificações simbólicas, como forma de ascender à segurança identitária recorremos às imagens de família, posição social, amor, nacionalidade, entre outras, que a cultura constrói e nos oferece.

Contemporaneamente, precisamos de narrativas compartilháveis, pois muito da tradição que era comum a todos nós foi contestada. "As aspirações que compartilhamos (e que compõem nossa cultura) não constituem um código nem valem um livro de normas. Elas vivem e se transmitem pelas histórias das quais gostamos, e especialmente por aquelas que são contadas para e por todos" (Calligaris, 2001).

Podemos pensar então que o cinema, a televisão, a literatura e, sim, a publicidade constituem o grande repertório das identidades possíveis; mais do que quaisquer outros meios, as mídias de massa contam histórias por e para todos. O consumo dessas histórias e imagens aparece então como aquilo que também viabiliza a nossa condição de sociedade (Baudrillard, 1991), o laço social. Logo, a publicidade torna-se instrumento central na constituição da subjetividade contemporânea, pois, ao consumir os produtosimagens, produzimos nossas identidades. Deriva-se daí que, para além do comércio de mercadorias, o que se processa é o comércio de modos de vida.

Alguns pensadores vão se mostrar bastante preocupados com essas mudanças, pois temem o que, no início do artigo, nomeamos de "precarização subjetiva", algo da ordem de um esgarçamento do laço social, seja por processos de homogeneização e enfraquecimento dos vínculos (Severiano, 2006) ou pelo atendimento ao imperativo do gozo (Bucci \& Kehl, 2004). Questão bastante polêmica cuja discussão foge ao escopo desse artigo, mas que julgamos pertinente referir, pois remete ao estatuto ético, ou à responsabilidade social, da publicidade.

Em geral, os publicitários são bastante refratários em relação aos discursos sobre influência apesar de, paradoxalmente, contratar profissionais para conhecer o comportamento dos consumidores a fim de buscar influenciar a compra. Esse rechaço talvez aconteça porque, subjacente a esses discursos, esteja a noção de influência direta e, com isso, o aceno a uma maior regulação na área. Não falamos de um lugar que preconiza a influência direta nem acreditamos na regulação como elemento indispensável e prioritário para outros modos de fazer publicidade. Acreditamos que, pelo fato de modos de vidas estarem sendo oferecidos aos sujeitos, a publicidade tem sim uma responsabilidade ética. Por isso perguntamos no início do texto: a publicidade poderia comunicar algo outro, de forma diversa, com outros efeitos? 
Acreditamos que sim e que os efeitos desse movimento não seriam importantes somente para os sujeitos, mas para o próprio campo, que, para além do incremento dos recursos tecnológicos, parece continuar atuando muito próximo ao que já ocorria há décadas atrás. Ainda vende. Mas, como referido nesse texto, saberes e poderes suscitam resistências por parte dos sujeitos e cada vez mais o cidadão-consumidor, diante de múltiplas exposições e interações, pode criar espaços por onde se movimentar.

Como fazer outra publicidade? É preciso construí-la, não existem estratégias standart. Argumentamos a favor da aposta na relação com o sujeito, que pode "se fazer de tolo", mas não é, e que tem diante de si caminhos para reinventa-se. Embora convivamos diariamente com o monólogo dos anúncios de corporações que buscam se "comunicar" conosco, existem tentativas de estabelecer um diálogo. Uma delas, embora ilegal, é o The Bubble Project ${ }^{5}$, um manifesto de arte urbana, iniciado em 2004 em Nova York e conduzido pelo artista Jet Lee. Consiste na aplicação de balões adesivos em branco como os de histórias em quadrinhos - em outdoors e todo tipo de publicidade urbana, onde os transeuntes podem livremente deixar sua opinião. Atualmente o projeto conta com desdobramentos em Amsterdan, Buenos Aires, Milão, Londres e Birmingham. Projetos como esses demonstram a vontade dos sujeitos em se fazerem ouvir e em participarem ativamente de um processo no qual se sentem alheios.

Existe uma diferença clara entre escutar os sujeitos enquanto consumidores - que querem fazer-se ouvir - e os estudos sobre o comportamento do consumidor. Através do olhar da publicidade, parecemos continuar exatamente como o psicanalista Dichter, no início do século XX, supunha que fôssemos: "consumidores sedentos pelo prestígio que as mercadorias conferem e assanhados" (Calligaris, 2008, p. 35).

Mas, como Calligaris (2008) pondera, não são as motivações banais (poder e sexo) que definem o sujeito, mas sua capacidade de inventar a vida, construir uma existência singular para além dessas motivações triviais. Por isso, escutar o consumidor pressupõe dar espaço à multiplicidade e à velocidade das transformações dos modos de subjetivação na contemporaneidade. É muito diferente de tomar os comportamentos - os desejos, as insatisfações e demandas enunciadas pelos sujeitos participantes de pesquisas de opinião pública ou de mercado - e transformar em uma (nova) tendência de mercado (Kehl, 2008).

Por uma ética da publicidade que entenda o processo comunicacional enquanto um estar junto, fazemos coro com Oliviero Toscani: "a publicidade geralmente nos diz como devemos consumir a vida. Deveria nos dizer como criá-la" (Calligaris, 1996, p. 75) ॠ famecos

\section{NOTAS}

1 Que se configura como o trabalho de estágio em Psicologia Social do segundo autor, orientado pela primeira autora, sistematizado como uma Ação de Extensão na UFRGS intitulada Psicologia Social \& Consumo: propondo novas relações. Nessa busca-se, no biênio 2008-2009, desenvolver ações de ensino, pesquisa e extensão junto aos operadores do consumo e à própria Universidade.

2 O uso corrente do termo publicidade no Brasil - e empregado no artigo - o aproxima ao termo advertising, definido pela American Marketing Association como: "veiculação de anúncios e mensagens persuasivas no tempo ou espaço comprados em qualquer media de massa pelas empresas, organizações não governamentais, agências do governo e indivíduos que procuram informar e/ou persuadir membros de um particular nicho de mercado ou audiência acerca de seus produtos, serviços, organizações ou idéias" (Simões, 2006, p.182-183). Já a propaganda dissemina idéias com a finalidade de promover os objetivos do emissor, não necessariamente favoráveis ao receptor; o que implica um processo de informação e de persuasão (Gomes, 2001). Ambas são estratégias que integram um contexto maior, denominado marketing, que visa "a análise, a planificação, a execução e o controle de programas destinados a produzir intercâmbios convenientes com determinado público, a fim de obter lucros pessoais comuns" (Kotler \& Keller, 2006, p. 320), o que depende também da adaptação e coordenação do produto, preço, promoção e distribuição.

3 Movimento de crítica que a psicologia vem fazendo dos seus discursos e práticas; no Brasil, desde os anos 70, buscam-se novos referenciais teórico-metodológicos para fazer frente a seu caráter político. Ver Hüning \& Guareschi (2005).

4 Tweens são crianças de 8 a 14 anos que se comportam como adolescentes; a palavra é uma contração de teen e between, adolescente e entre na língua inglesa. Irmães são mães que, em aparência e comportamento, figuram como irmãs de suas filhas. Kidults são jovens adultos, na faixa de 30 anos, que seguem morando com pais e são adeptos a videogames e outros hábitos e comportamentos associados aos adolescentes; composição entre as palavras kid e adult, no inglês, criança e adulto.

5 http://www.thebubbleproject.com/

\section{REFERÊNCIAS}

BAUDRILLARD, Jean. A sociedade de consumo. Lisboa: 
Edições 70, 1991.

BAUMAN, Zygmunt. Vida para consumo. Rio de Janeiro: Jorge Zahar, 2008.

BIGHETTI, Heraldo. Propaganda subliminar e outras lendas urbanas. Revista de ESPM, 10 (2), 43-51, 2003.

BUCCI, Eugenio; KEHL, Maria Rita. Videologias. São Paulo: Boitempo, 2004.

CALLIGARIS, Contardo. Crônicas do individualismo cotidiano. São Paulo: Ática, 1996.

. Os fiéis a Harry Potter. Folha de São Paulo [On line]. Disponivel em: <http://www1.folha.uol. com.br/fsp/ilustrad/fq2211200127.htm, 2001>

. Quinta-coluna. São Paulo: Publifolha, 2008.

FISCHER, Rosa Maria Bueno. Adolescência em discurso: mídia e produção de subjetividade. Tese de doutorado não-publicada, Universidade Federal do Rio Grande do Sul, 1996.

FONTENELE, Isleide Arruda. The coolhunters. In: Lua Nova, 63, p. 163-177, 2004.

- Psicologia e marketing: da parceria à crítica. Arquivos Brasileiros de Psicologia, 60(2), p. 143-157, 2008.

GOMES, Neusa. Publicidade ou propaganda? É isso aí! Revista FAMECOS, 16, p. 111-121, 2001.

HENNIGEN, Inês. Subjetivação como produção cultural: fazendo uma outra psicologia. Psicologia \& Sociedade, 18 (2), p. 47-53, 2006.

HOBSBAWM, Eric. A era dos extremos. São Paulo: Companhia das Letras, 1995.

HÜNING, Simone; GUARESCHI, Neusa Maria de Fátima. Efeito Foucault: desacomodar a psicologia. In: N. M. F. Guareschi; S. Hüning (Orgs.), Foucault e a psicologia (p.107-127). Porto Alegre: Edipucrs, 2005.

JACKS, Nilda \& PIEDRAS, Elisa. Estudos de recepção da publicidade: explorando as pesquisas da década de 1990. Comunicação, Mídia e Consumo, 7 (3), 113-130, 2006.

KEHL, Maria Rita. A fratria órfã: conversas sobre a juventude. São Paulo: Olho d’Água, 2008.

KOTLER, Philipe; KELLER, Kevin. Administração de Marketing. São Paulo: Prentice Hall, 2006.

MAFFESOLI, Michel. A comunicação sem fim. In Martins, F. M; Silva J. M. (Orgs.), A genealogia do virtual (p.20-32). Porto Alegre: Sulina, 2008.

MORIN, Edgar. A comunicação pelo meio. In Martins, F. M; Silva J. M. (Orgs.), A genealogia do virtual (p.11-19). Porto Alegre: Sulina, 2008.

PARENTE, André. A comunicação como nova dimensão da produção de subjetividade. In Guareschi, N. (Org.), Estratégias de invenção do presente: a psicologia social no contemporâneo (p. 55-66). Porto Alegre: Edipucrs, 2004.

ROCHA, Silvia Pimenta Velloso. Yo no creo en brujas, pero que las hay, las hay: a publicidade, o consumo e a crença descafeinada. Comunicação, Midia e Consumo, 9 (4), p.127-137, 2007.

SEVERIANO, Maria de Fátima Vieira. Pseudoindividuação e homogeneização na cultura do consumo: reflexões críticas sobre as subjetividades contemporâneas na publicidade. Estudos e Pesquisas em Psicologia, 6 (2), p. 105-121, 2006.

SOUSA, Jorge Pedro. Elementos de teoria e pesquisa da comunicação e dos media. Porto: BOCC Biblioteca Online de Ciências da Comunicação [On line]. Disponível em: <http://www.bocc. ubi.pt/pag/sousa-jorge-pedro-elementosteoria-pequisa-comunicacao-media.pdf >, 2006.

SIMÕES, Cassiano Ferreira. A publicity e a publicidade (para além da propaganda). Comunicação, mídia e consumo, 6 (3), p. 179-200, 2006.

TOSCANI, Olivieiro. A publicidade é um cadáver que nos sorri. Rio de Janeiro: Ediouro, 1996.

WACHELKE, J. F. R; Segala, M. Interdisciplinaridade em psicologia social e comunicação social [On line]. Disponível em: <http://lakh.unm.edu/ handle/10229/81870>, 2005

WOLTON, Dominique. É preciso salvar a comunicação. São Paulo: Paulus, 2006. 